\title{
Study on Sustainable Development of Traditional Furniture Technology
}

\author{
Kun Xue , Yan Sun ${ }^{2, ~ *, ~ L a i c h e n g ~ Y a n g ~}{ }^{3, ~ *, ~ A n ~ M a o ~}{ }^{3, \text { * }}$ \\ ${ }^{1}$ Academy of Applied Design, Shandong University of Art \& Design, Jinan, China \\ ${ }^{2}$ College of Art, Shandong Agricultural University, Taian, China \\ ${ }^{3}$ College of Forestry, Shandong Agricultural University, Taian, China
}

Email address:

13954179079@139.com (Kun Xue), 58579573@qq.com (Yan Sun), yanglcc@126.com (Laicheng Yang), dannymaoan@126.com (An Mao)

${ }^{*}$ Corresponding authors

\section{To cite this article:}

Kun Xue, Yan Sun, Laicheng Yang, An Mao. Study on Sustainable Development of Traditional Furniture Technology. American Journal of Environmental Science and Engineering. Vol. 4, No. 3, 2020, pp. 49-53. doi: 10.11648/j.ajese.20200403.14

Received: September 4, 2020; Accepted: September 15, 2020; Published: September 25, 2020

\begin{abstract}
As a relatively independent type of furniture, Chinese traditional furniture has a long history. It has the characteristics of simple modeling, rigorous structure and fine workmanship, which is an excellent combination model of science and art. Entering the modern society, the development of traditional furniture has opened a new stage, which also encountered some problems. This paper summarized the problems existing in the process of traditional furniture technology inheritance, analyzes the problems, and puts forward the corresponding countermeasures. In order to adapt to the development of the times and meet the needs of consumers to cope with the fierce competition, innovation has become an inevitable choice for many enterprises. Therefore, in the field of traditional furniture industry, in addition to learning and inheriting skills through traditional methods, it is necessary to integrate innovation, modern market awareness, rethink business strategies, and try to introduce some high-tech elements into the rapid changes of the external environment. With the help of modernization, technology and information technology, enterprises can find new development impetus to enhance competitiveness, and combine modern furniture technology with traditional furniture technology. Modern lifestyles should be organically combined to get better inheritance. This study can also provide valuable information for the research on education and training of undergraduate and graduate students within forestry engineering related disciplines.
\end{abstract}

Keywords: Traditional Furniture, Sustainable Development, Technology, Innovation

\section{Introduction}

Furniture plays an important role in China's traditional manufacturing industry, which has high practical value and cultural and artistic value. As a relatively independent school of furniture, Chinese traditional furniture has a very long history. It has the characteristics of simple modeling, rigorous structure, and fine workmanship, which is an excellent combination model of science and art. Entering the modern society, the development of traditional furniture has opened a new stage, which also encountered some problems. This paper summarized the problems existing in the process of traditional furniture technology inheritance, analyzes the problems, and puts forward the corresponding countermeasures.

\section{Problems and Analysis of Traditional Furniture Technology}

\subsection{Crisis of Inheritors}

In the past, in rural areas, children who had finished junior high school would choose to learn furniture making, architecture or other skills. According to the survey, most of the craftsmen are aged from 16 to 18 . This age group is also a critical period to prepare for college, so people need to choose between "learning art" and "going to college". Nowadays, more and more people hope that children can enter a good university and find a good job in the future. Therefore, even if the income is good, craftsmen are rarely 
willing to learn the traditional carpentry skills and continue to work in the furniture industry [1].

Most young people are also reluctant to engage in furniture related work for two reasons: first, there is no independence at the beginning of furniture making, and it is relatively monotonous. Traditionally, it takes three years and four months for apprentices to be independent, but now there is a lack of such a learning environment. Secondly, they work long hours, work hard, have no fixed workplace and welfare protection, and their income is generally low. Although the wage of carpentry increases with the increase of working years, it is not like other industries that can get higher income in a short period of time. In addition, people generally believe that learning furniture making needs talent, so it is not necessarily possible to obtain higher income if we persist in furniture making for several years. Therefore, it is more and more difficult to recruit apprentices of traditional furniture skills [2-4]. For traditional craftsmen, woodwork is not only a profession, but also a part of life and interest. For most of the young practitioners, it is just a job, and they can change jobs at any time to seek other development. Therefore, in the view of young employees, this traditional process has not been attractive enough [5].

Among the rural craftsmen, the vast majority of them think that they are only craftsmen. They regard furniture craft as a skill to support their families. Few people think they are artists, and few want to develop in the direction of artists. In contrast, urban craftsmen hold more discourse power, have a higher status than rural craftsmen, and their furniture has gained higher recognition in terms of artistry. However, the works of most rural craftsmen are anonymous, and the works of a few masters are regarded as "works of art". In addition, the students cultivated by the existing vocational education system can hardly be respected as the craftsmen who learned skills through apprenticeship in the past. This situation is different from other kinds of arts and crafts works, which directly leads to the decline of folk craft furniture.

There are great differences in the income level of craftsmen. If they get the title of provincial master or above, it is easy to gain social and economic benefits, and the income is much higher than that of ordinary craftsmen. In addition, due to the prosperity of the mahogany furniture market at that time, there were many merchants selling and wholesaling finished products in the streets of mahogany furniture producing areas. These merchants were often more successful than the masters with titles, which eventually led to huge differences in income between merchants and craftsmen. In recent years, due to the downturn of high-end furniture market, the traditional sales mode along the street has been greatly affected. Therefore, in addition to fame, the ability of craftsmen to manage factories or workshops, or the relationship between people and other factors largely determines the income.

Table 1. The difference between mahogany furniture and traditional folk furniture.

\begin{tabular}{lll}
\hline & Mahogany furniture & Traditional folk furniture \\
\hline Materials used & $\begin{array}{l}\text { Mahogany (represented by the imported wood such as Ramulus } \\
\text { alkekengi, Dalbergia macrocarpa, Pterocarpus erinaceus, etc.) }\end{array}$ & $\begin{array}{l}\text { Traditional furniture materials in this area, such as elm, } \\
\text { beech, catalpa, etc } \\
\text { Mode of production }\end{array}$ \\
$\begin{array}{lll}\text { Skill level } \\
\text { Hainting method }\end{array}$ & Semi-skilled or no carpentry Foundation & $\begin{array}{l}\text { Semi manual and semi mechanical, single or several } \\
\text { order production }\end{array}$ \\
Style & Chemical coating (polyester paint, etc.) or hot wax & Skilled carpenter \\
Sales area & Marketization & Lacquer \\
\hline
\end{tabular}

\subsection{The Process Is Partial to Surface}

In the long-term development process of traditional woodwork, it not only contains a set of knowledge about wood technology itself, but also forms a set of special industry organization system and rules, and forms inherent wood material culture and spiritual culture in its mutual correlation. In the traditional manual production mode, craftsmen make furniture according to the needs of consumers. From raw materials to finished products, the craftsman or his apprentice will complete the whole process. They are very familiar with the production technology of traditional furniture and the allusions behind the patterns. The workers who work in the factory are only responsible for the operation of the machine, processing parts or semi-finished products. They do not have the deep feeling of the products in the past, nor can they realize the sense of achievement brought by the production process and the completion of the works. For example, new Chinese furniture, as a derivative of traditional furniture, is more in line with the aesthetic concept of modern people in form, but most of the current new Chinese furniture is a pile of Chinese symbols, and the deep connotation of the form has not continued. Even these symbols, young masters engaged in carving work do not necessarily understand the implied meaning.

The essence of folk art products is economic production, which is the production of practical products used by producers to supplement agricultural income. However, if the impulse of creation points to the goal of utility, in other words, if the traditional art is regarded as a profitable business, its artistry may be reduced to a certain extent.

The traditional process is generally more cumbersome and has many processes. One of the reasons is that it is limited by the conditions of the times. In order to achieve a delicate and beautiful effect, it needs a variety of processes to cooperate. The development of science and technology provides a technical basis for the transformation of traditional furniture technology, such as replacing low efficiency and dangerous 
sawdust pile with drying kiln, and using automatic woodworking equipment. Although the changes of these technical tools make the craftsman no longer need to touch the materials directly by hand, they may not bring negative effects on the products, because the progress of equipment can better control the quality of products and make more efficient use of raw materials [6-8]. However, if it is to obtain more benefits, rather than to ensure the quality and improve the artistic level, the transformation of this kind of technology will become the simplification of the traditional craft at the cost of sacrificing quality. Therefore, traditional craftsmen are often difficult to compete with large-scale merchants, and finally have to give up the complex production techniques. Some will turn to wholesale business or buy semi-finished products at a low price and sell them after a little renovation. This change makes it difficult for the traditional furniture industry to develop a living mode dominated by craftsman creation similar to other arts and crafts types [9].

\subsection{The Diversity of Folk Furniture Decreased}

In the process of inheritance, a typical example of the decline in diversity is the disappearance of folk furniture styles in various regions. Here, the development of "mahogany" furniture is compared with folk furniture: as shown in Table 1, "mahogany" furniture is made of materials (basically imported materials) specified in the national standard of "mahogany"; traditional folk furniture is made of local materials and made by traditional crafts in various regions, also known as firewood furniture. The furniture is made of local materials record: old style furniture is divided into hardwood and firewood. The most expensive is red sandalwood. It is also called table and chair shop or dowry shop. It is strong and durable. The way to do it is to peel the skin carefully and bake it to dry. For example, Long Shun Cheng, the inheritor of "jingzuo" furniture, was also a table and chair shop that produced wood furniture before the merger.

Folk furniture is durable, rich in local characteristics, with creative, simple, personalized characteristics. However, these imaginative works cannot attract people's attention because they do not conform to the stereotype of the collection and academic circles on the characteristics of classic traditional furniture. In particular, in the evaluation system of traditional furniture, folk furniture is called "folk" furniture, which is opposite to "classic" furniture with a single standard to evaluate materials and shapes. The number of so-called "classic" works is extremely limited, which is basically fixed in some classic books (Beijing craftsmen call "some on the spectrum") and some hardwood furniture appearing in auctions. In order to pursue more profits, the efficient flow production system is used to replace the manual operation step by step. As a result, the regional style of traditional folk furniture was replaced by the unified market fashion style, which led to the unification of material and style.

In the past ten years, the number of employees in several major producing areas of mahogany furniture has increased significantly compared with that of more than ten years ago, while the employment of traditional folk furniture industry has declined sharply and the aging is serious. With the decrease of employees, the original rich and diverse folk furniture styles full of regional characteristics are on the verge of disappearing. For example, the willow armchair, which has been widely used in northern China, has different shapes in different regions. It has strong rationality in material, technology and ergonomics, and has the characteristics of unconstrained and unsophisticated in aesthetics. Unfortunately, most of the craftsmen who make willow armchairs give up this traditional craft because of their income [10].

\subsection{The Materialistic View of Materials Prevails}

People's pursuit of materials has promoted the development of some arts and crafts categories, such as jade carving, mahogany furniture and other industries, which have a high market recognition and good development, partly due to the scarcity of materials. On the other hand, because of the long-standing idea of valuing materials and neglecting crafts, the normal market order has been destroyed and the inheritance of some categories in skills has been restricted. In the traditional furniture industry, people's pursuit of materials is particularly obvious. The materials used by these useful "things" provide opportunities for human beings to increase their desires and show their identities.

Take mahogany furniture as an example. In fact, the extensive use of mahogany furniture has caused serious impact on the forests and ecosystems in the felled land. Most of the wood species in the standard of mahogany furniture come from the tree species of tropical rainforest, and many of them are endangered species. For example, chicken wing wood, which is often used to make flooring and furniture, is one of the endangered species listed on the IUCN Red List. Only material theory confuses the concept of mahogany and traditional furniture, neglecting the structure, technology and cultural value of traditional furniture. The "hot" of mahogany furniture reflects a certain social phenomenon. If the illustrative furniture represents the literati culture of Ming Dynasty, mahogany furniture reflects the material and secular culture seeking for colorful and bright colors. Now only a few people can consume it. The market is getting smaller and smaller, and it is gradually divorced from the masses of consumers. In this case, it leads to the stagnation and abnormal development of traditional furniture [11].

\subsection{Problems of Evaluation Mechanism}

In terms of market evaluation mechanism, collectors, curators and art shop operators usually make judgments on the quality of works. The social status and geographical position of creators are far away from them. The criteria for judging works by those involved in the art market affect the creative 
direction of craftsmen, which often reflect the needs of international markets and exporters, rather than localized design and cultural preferences, although for most of the past, such products have obvious stylistic features in the country of origin. Especially in the situation that western contemporary art and traditional "classic" art occupy a dominant position, the phenomenon that craftsmen deliberately change folk modeling language to meet the needs of the market is becoming more and more prominent. For the above reasons, many traditional craftsmen can only maintain some traditional styles, they do not agree with or have no ability to enter the current new Chinese furniture market, unable to meet the modern diversified needs, and gradually withdraw from the mainstream market.

\section{Coping Strategies}

\subsection{Combining with Modern Advanced Technology and Technology for Innovation}

Traditional furniture has been accumulated for a long time. However, with the change of life style, traditional furniture is becoming more and more rigid in modeling and has limitations in ergonomics. Therefore, from the perspective of cultural continuity, whether it can make full use of its cultural spirit and elements and apply it to modern living space is a direction worthy of discussion. In addition to cultural factors, contemporary Chinese furniture design should have a broader vision and a deeper understanding of the essence. Compared with the past, modern processing means have greatly improved product quality and manufacturing efficiency. Therefore, it is necessary to carry out modern transformation of traditional structure, rather than confined to the discussion of "new Chinese style" style. Such transformation will produce new forms in line with the characteristics of the times.

The progress of technology will inevitably bring about changes in the concept, methods and methods of artistic creation, and at the same time, it also causes the possibility of mass reproduction and wide dissemination of art. From this point of view, the progress of technology makes it easier for Chinese traditional classic art works to realize the popularization and popularization. Therefore, how to provide more resources and opportunities for traditional wood craftsmen, guide them to give full play to their original wood processing experience, and realize the technical transformation is a problem that the government or relevant organizations should consider when formulating policies.

\subsection{Strengthen Research and Record, Establish Standards and Standardize the Market}

In terms of academic research, in recent years, the exploration of traditional furniture technology innovation has promoted the development of modern Chinese furniture to a certain extent. But in the traditional furniture technology, modeling and style evolution, there are few in-depth research and records. Therefore, scholars should pay more attention to the traditional furniture which is still inheriting and can be fully integrated into life, and preserve the experience of creators through academic research. In terms of market, due to the high popularity and market acceptance of classic products in traditional furniture, many products are sold under the names of "jingzuo furniture", "suzuo furniture", "xianzuo furniture" or "guangzuo furniture", which leads to a mixture of good and bad products. Many of these products deviate from the original intention of traditional handicraft in material selection, drying, ingredients and tenon mortise structure. Therefore, it is suggested that relevant departments should work together with experts and scholars of traditional furniture enterprises, as well as the representative inheritors, artists and craftsmen of traditional furniture production technology to formulate the design and structural process specifications of traditional furniture. On the basis of qualified products, the specification of material name, material testing method, mechanical properties and other technical conditions of traditional furniture are stipulated, which provides the basis for the detection and inspection of traditional furniture products, and provides the classification and grading standards of traditional furniture, so as to guide the production and design.

\subsection{Keep Pace with the Times and Innovate the Inheritance Mode of Traditional Furniture Technology}

Under the apprenticeship system of early traditional furniture, it took three years and four months to get out of school. This kind of long-time training emphasizes the skill. Although it can be passed on through strict education and even restriction, with the loss of people engaged in crafts after industrialization, many handicraft skills have been replaced by machines, which is difficult to continue through word of mouth in modern society. In the past, most of the workshops and factories where apprenticeship was taught mainly focused on training industrial professionals, and inheritance was not the main purpose; in modern times, the masters, aware of the problem of the continuity of technology, began to actively recruit apprentices, hoping that the craft could continue to be passed on.

In view of the problem of inheritance mode, it is necessary to carry out educational planning on the cultural value of traditional furniture industry, for example, to increase the richness of its educational experience through activity design based on the process culture education in primary and secondary schools. In addition, we can strengthen the experience service of craft culture according to the customer consumption record, strengthen the resource exchange with other units, and promote the thematic joint marketing activities, so as to strengthen the characteristics of the craft theme.

\section{Summary}

At present, almost all the traditional furniture management methods are still traditional: operators rarely consider the 
marketing and management system, most of them are based on their own inherent business concept, mainly selling single piece, so it is difficult to compete with large-scale furniture enterprises' exclusive stores. In addition, when encountering a series of problems, such as high land rent, few guests and slow turnover, the operators can only give up operation. Therefore, in the field of traditional furniture industry, in addition to learning and inheriting skills through traditional methods, it is also necessary to integrate modern market awareness, rethink business strategies, and try to introduce some high-tech elements into the rapid changes of the external environment. With the help of modernization, technology and information technology, enterprises can find new development impetus to enhance competitiveness, and combine traditional furniture technology with traditional furniture technology Modern lifestyles should be organically combined to get better inheritance. This study can also provide valuable information for the research on education and training of undergraduate and graduate students within forestry engineering related disciplines.

\section{Author Contributions}

The Manuscript was written through contributions of all authors. All authors have given approval to the final version of the manuscript.

\section{Conflicts of Interest}

The authors declare that they have no competing interests.

\section{Acknowledgements}

The research was supported by funding from research project of teaching reform in Shandong Province (Project No: M2018X182) and key research project of graduate education reaching reform in Shandong Agricultural University (Project No: JYZD2018014).

\section{References}

[1] Gao W. X, Wu Z. H, Yu J. H (2019) Analysis on the Characteristics of Traditional Handicraft of Woodcarving by Su-style Furniture in Ming and Qing Dynasties. China Forestry Products Industry, 56 (9): 43-47.

[2] Gao W. X, Wu Z. H, Yu J. H (2019) Multidimensional Preference Analysis of Su-style Furniture Wood Carving in Ming and Qing Dynasties. China Forestry Products Industry, 46 (7): $39-43$.

[3] China Forest Products Industry Association, State Forestry Bureau Forest Industry Planning and Design Institute. China Wood Based Panel Industry Report 2019. 2019.

[4] Xu H. F, Dai X. D, Ye L, Zhang Y, Wang J. Y (2019) Problems and Suggestions on the Dongyang Mahogany Furniture Industry in Zhejiang Province. China Forestry Products Industry, 46 (6): 41-44.

[5] Zhang J (2015) Planning of forest resin board integrated industry demonstration area in Ji'an, Jiangxi Province. China Forestry Products Industry, 42 (4): 47-53.

[6] Yan Z. H, Li K. Z (2019) Research on Module System of Ming-style Furniture. China Forestry Products Industry, 46 (7): 44-47.

[7] Li H. B, Lin Z. F (2019) Study on forestry industry ecology based on circular economy. Jiangxi Agriculture, 12: 88-89.

[8] Yu J. H, Gao W. X, Wu Z. H (2019) Relevance Analysis between the Proportion of Woodcarving Decoration and Visual Perception of Su-style Furniture in Ming and Qing Dynasties. China Forestry Products Industry, 56 (12): 52-57.

[9] Cui W. Z (2019) Study on the development of forestry industry from the perspective of circular economy. Science and Technology Innovation Herald, 16 (19): 255-257.

[10] Yu X. Y, Hu F. Y, Guo Q (2019) Foshan Paper Cutting Art in the Application of Modern Furniture Design in China. China Forestry Products Industry, 56 (11): 56-60.

[11] Liu C, Sun J. R (2020) Study on New Chinese Style Children's Furniture Design Based on the Concept of Chinese Traditional Culture. China Forestry Products Industry, 57 (1): 58-61. 